\title{
Negritud, creolidad, indianidad, mundialización
}

\author{
Negritude, Creolitude, Indianity, Globalization \\ Negritude, crioulidade, indianidade, mundialização
}

\section{Jean Bernabé}

UNIVERSITÉ ANTILLES ET DE LA GUYANE, MARTINIQUE

Profesor de literatura y cultura caribeña en la Université Antilles-

Guyane. Ha publicado varios libros, entre ellos los ensayos Fondal-

Natal (L'Harmattan, 3 vols. 1992), Fondas-Kréyol (1982), Eloge de

la créolité, con Patrick Chamoiseau y Raphaël Confiant (1989),

La graphie créole (Ibis Rouge Editions, 2001), y las novelas Le

bailleur d'étincelle (Écriture, 2002), Le partage des ancêtres (2004).

Correo electrónico: jean.Bernabe@martinique.univ-ag.fr

Ensayo

Traducción de Daniel Vergel. Profesional en Estudios Literarios de la Pontificia Universidad Javeriana, Bogotá. Correo electrónico: danielvergel90@gmail.com Documento accesible en línea desde la siguiente dirección: http://revistas.javeriana.edu.co

doi: $10.11144 /$ Javeriana.cl19-38.ncim

Cómo citar este ensayo:

Bernabé, Jean. "Negritud, creolidad, indianidad, mundialización". Cuadernos de

Literatura 19.38 (2015): 58-64 http://dx.doi.org/10.11144/Javeriana.cl19-38.ncim 
Señor Rector,

Señoras y Señores,

Querida juventud de Escuelas y Colegios,

En la ocasión que nos reúne en torno al cumpleaños de Aimé Césaire y a la celebración conjunta del $150^{\circ}$ aniversario de la llegada a tierra martiniqueña de las primeras embarcaciones indias, me agradaría dirigirles algunas palabras, las que me gustaría sembraran y fecundaran en ustedes los gérmenes de una nueva esperanza, en contravía al paso en el que parece ir nuestro planeta.

Una visión fija del universo coloniza nuestras representaciones, hipoteca nuestra relación con la idea misma de civilización y acciona nuestros comportamientos. La civilización no tiene centro, no entendamos aquí un centro vivible, respirable, en pocas palabras, un centro a la medida de la condición humana. La civilización está por todas partes y en todos los lugares a donde el hombre se dirija. En cambio el etnocentrismo lo conocemos a la fuerza. Si le sucede, aquí o allí, fingir morir una noche, es para renacer mejor de sus cenizas al siguiente día. El etnocentrismo, que es una de las cosas más comunes en el mundo, aparece con más evidencia donde los que, hinchados de ingenua omnisciencia tanto como de perversa voluntad de poder, dirigen el curso del mundo y pretenden conservar el control, discutidos en esto por la cohorte de aquellos que, por motivos idénticos, les disputan la preeminencia.

Me gustaría que ustedes reflexionaran sobre las casualidades bastante surrealistas de la fonética, que hacen que los nombres de Julio César y Aimé Césaire hayan estado reunidos en una misma semejanza. Sugiriendo de un lado un inmenso imperio temporal, el de la conquista y las armas que hieren y del otro lado, un insondable imperio imaginario, el de la búsqueda, el de las "armas milagrosas", el de la poesía que cura. Poesía soberana de Aimé de Césaire, poesía para liberar un pueblo de sus cadenas mentales, poesía para enseñar la belleza de ser uno mismo, de ser Negro "poroso a todos los hálitos del mundo". Al punto que, en su esfuerzo por sacudir el yugo de la dominación anglosajona, los escritores quebequenses de la Revolución Tranquila se proclamaron negros, precisamente porque se reconocieron totalmente en el mensaje cesairiano. Es decir, la fuerza metafórica y simbólica de la negritud que, lo habremos adivinado, es todo menos una postura racista.

En Cuaderno de un regreso al país natal, al lado de la mención del "hombrejudío", está la de los hijos de la India, que por corta no es la menos significativa: el poeta se concibe entonces tanto como "hombre-devastación", "HombreHindú-de-Calcuta". Faltó esperar al último tercio del siglo pasado para que los descendientes antillanos de los indios, desembarcados desde 1853, comprendie- 
ran que este mismo mensaje cesairiano les requería reconciliarse con las raíces ancestrales más cercanas, en realidad, más el Ganges o el Indo que el Nilo o el río Congo. Así entonces, Aimé Césaire habrá logrado, dentro del mismo movimiento dialéctico, afirmar la universalidad de la negritud y la apertura de esta sobre la diversidad del mundo, sobre esto que Chamoiseau, Confiant y yo llamamos la "diversalidad" en nuestro ensayo titulado Elogio de la creolidad (publicado en 1989, en Editions Gallimard). Es por esto que proclamamos que éramos por siempre hijos de Aimé Césaire.

Encerrándome lo menos posible en las polémicas y controversias del colegio, no puedo abstenerme de recordar el propósito de Aimé Césaire, según el cual la creolidad es un departamento de la negritud. En esto él tiene razón. Razón en el plano de la filiación. Sin embargo, en el ámbito lógico, es más bien al contrario: igual que la indianidad (que algunos, políticamente poco correctos, comienzan a llamar la "koulitude", pretendiendo abarcar así el escupitajo y los estigmas del desprecio), África es uno de los componentes de la creolidad, es decir, una visión del mundo que articula las culturas en un incesante diálogo, en una relación en la que interactúan diversas herencias ancestrales. Se trata de un componente mayor seguramente, pero desde luego no el único de nuestra realidad antropológica. De golpe toda distinción de orden departamentalista pierde cualquier interés cuando tomamos en consideración la dimensión fundadora del paso césairiano. La negritud no es obsoleta. Ella estará vigente en tanto que haya negros. Y habrá negros tanto como habrá seres despreciados, rebajados, excluidos de ellos mismos y de su autenticidad.

A escala de las Antillas, que son una prefiguración todavía borrosa del mundo a venir, la compartición de los ancestros es la condición de una cohabitación nueva entre pueblos y culturas. Hay que dejar de magnificar la raíz única para celebrar el origen múltiple. Pues no siendo ni africanos, ni europeos, ni asiáticos, somos todo eso a la vez. Nuestra identidad no es negativa sino positiva, no está por sustracción sino por acumulación, agregación.

Por paradójico que pueda parecer, no tenemos un deber de memoria sino también un deber de olvido. Pero el deber de olvido solo será posible cuando hayamos cumplido el de la memoria y este a través de una exaltación de los lugares y oportunidades más adecuados. La imperiosa necesidad en la que estamos, de pensarnos, supone un anclaje en el pasado y una proyección hacia el futuro.

$1 \quad$ La palabra "kouli" derivada de coolie (término despectivo para referirse a los esclavos u obreros asiáticos en el sur de China, India y Filipinas durante los siglos XIX y XX), es usada en el Caribe para designar a las personas provenientes de India o sus descendientes. N. del T. 
Si estamos seguros de nuestras diversidades pasadas y presentes, no tenemos ninguna garantía de conservarlas. Porque estamos desde ahora en el mundo. En la totalidad del mundo, en el riesgo y la oportunidad del Todo-Mundo, para retomar la expresión de Edouard Glissant.

En efecto, no se trata de hacer comentarios sobre lo que se está volviendo una realidad ineludible, a saber, que el universo racional y lógico que nos fabrican se acerca tanto a lo absurdo como a lo inverosímil. Mejor todavía: ja lo inaceptable! En esta condición y en la negación de esta última se encuentra el fundamento de una postura, que para agilizar quiero asociar al realismo maravilloso. De ninguna manera surrealismo, sino realidad recia y por lo tanto fantasmagórica, en referencia a la que somos obligados a vivir la existencia que nos fue concedida. Allí se encuentra todavía la pulsación de nuestros seres. Allí se encuentra el secreto de la creolización, movimiento continuo e imprevisible que yo no tendría cuidado de confundirlo con el mestizaje puro y simple y que se caracteriza por lo que llamaré la compartición de ancestros.

La compartición de ancestros, esta es la verdadera exigencia moderna. Las condiciones intelectuales, políticas e ideológicas de una mirada sobre nosotros mismos cambiaron. No estamos más en la era donde la afirmación "nuestros antepasados Galos" estigmatizada, denunciada por la sarcástica retórica fanoniana ${ }^{2}$ de Pieles negras, máscaras blancas constituía una marca -más bien grotesca- de nuestra alienación cultural y psicológica. Hoy estamos en proceso de acceder a una visión más dialéctica de las cosas, visión respecto de la cual nos importa reconocer y asumir también "nuestros ancestros Galos". Con una condición no obstante: que todos los antillanos, Békés comprendidos, puedan también proclamar: "nuestros ancestros Bambaras, Mandinga, Dogón, Tamil y me quedo corto".

La compartición no es una imposición ni concesión de ancestros, estas conductas fueron tomadas prestadas por la generosidad republicana. El compartir es y no es más que reconocimiento del otro y fruto de un libre diálogo de las culturas. Pero, ¿ ¿cómo hacer dialogar a todas las culturas? Ahí está una pregunta grande y difícil que no se resuelve con vuelos líricos y frases hondas. Hace falta, más que un taller, una verdadera obra, mejor todavía: una falsificación. Es una exigencia absoluta la de desarrollar nuestras capacidades imaginarias y simbólicas, instrumentos irremplazables de la cultura, nuestra única patria. Y lo que

2 Hace referencia a Frantz Fanon. Pensador francés que fue clave en los problemas de la descolonización y de la psicopatología de la colonización, sus obras son fundamentales en los estudios poscoloniales. N. del T. 
nos hace falta no es la cultura del mestizaje, sino el mestizaje de las culturas. Yo quiero, por un paradójico préstamo de Glissant, denunciar las secuelas raciológicas que rodean ciertas concepciones de la creolización confundida con un simple mecanismo biológico: sean estereotipos, en la más grande ingenuidad y la mejor conciencia, infestan la exaltación del mestizaje que se supone crea seres más bellos, más dotados que los resultantes del no-mestizaje. Tengamos cuidado: remplazar el ideal de la pureza racial por el de la mezcla seguramente no es un progreso. Ni en el orden del pensamiento, ni en el de la ética.

No, el mestizaje biológico no sabría ser un valor en sí mismo. En este aspecto la historia antigua y la reciente de Estados Unidos es muy diciente. Los padres fundadores de la nación (estadounidense, debería decir) tenían por ideal hacer un melting-pot, es decir, un crisol. Pero entre el ideal abstracto y la realidad histórica se cavó una inmensa fosa. Pues el supuesto país del melting-pot es precisamente el de la discriminación, se impuso bajo formas sociales y políticas extremas, no muy lejanas de las del apartheid sudafricano. Estados Unidos es tomado a menudo como ejemplo de comunitarismo. Pero es importante analizar las características de este comunitarismo. La naturaleza de este se torna en el fondo incomprensible, si no ponemos en evidencia un dato capital: en los Estados Unidos, encontramos bajo una representación de microcosmos el abanico completo de los grupos étnicos del mundo. Estos grupos viven a la vez relativamente separados y forzadamente puestos en coherencia a través de la hegemonía política instaurada por la lógica WASP (White Anglo-Saxon Protestant).

Precisamente, la sociedad estadounidense es, lo sabemos, una pirámide hecha de estratificaciones, que es producto de eliminaciones sucesivas, como testimonia el término WASP que me propongo analizar brevemente:

white: a pesar de la filosofía idealista de los padres fundadores, los no-blancos no tuvieron voz en el capítulo (los primeros pueblos, los amerindios fueron atropellados, casi conducidos a la extinción, los negros importados, reducidos a la esclavitud, no obtuvieron la plenitud de derechos civiles sino desde hace algunas décadas).

anglo-saxon: así estuviera en el seno del grupo de origen europeo, hubo preponderancia del elemento anglosajón sobre el latino.

protestante: hubo una preponderancia del grupo religioso protestante sobre todos los otros.

Si hay melting-pot en EEUU, proviene evidentemente no de una mezcla genética de las comunidades, sino de una imposición política y cultural organizada por la comunidad más poderosa y para generalizar la american way of life. El imaginario de los descendientes de los esclavos fue captado y así estuvieran liberados de sus 
cadenas físicas e institucionales, estaban sumergidos en una esclavitud todavía más insidiosa que la pasada y de la que no es seguro que pudieran libertarse. Aimé Césaire ya había presentido esto al decir que de todos los imperialismos, el imperialismo americano era aquél del que no se escapaba nunca.

El proceso que se despliega en Estados Unidos se está extendiendo al conjunto del planeta en el marco de lo que es conveniente llamar mundialización. Este tipo de mundialización no es una fatalidad en sí, pero no se ve qué fuerzas la podrían desviar de la trayectoria iniciada en EEUU, en complicidad más o menos conflictiva, más o menos asumida, con las potencias instauradas por este gigante. De hecho, si me permiten este juego de palabras, esta mundialización conlleva a la inmundialización ${ }^{3}$. No es necesario para nada ser miembro del movimiento ATTAC $^{4}$ para convencerse de esto. Una lógica de antiglobalización de la que no encontramos aún las configuraciones se impone, sin embargo, una reflexión sobre la creolización no puede sino ponerla de relieve.

El ejemplo estadounidense, del que acabo de enumerar sus características esenciales, nos prueba que las lógicas políticas no son simple y llanamente superponibles a las lógicas de pertenencia raciológicas (que son lógicas esencialmente ideológicas). Si no se admite esto, no se puede comprender por ejemplo, que el general Colin Powell sea un simple producto estadounidense, al servicio de una visión estadounidense y WASP, una visión no solamente dominante sino estructuradora de la nación. Cualquier otra visión posible en este país solo puede ser marginal, marginalizada. De ahí que la noción de African American no sea sino retórica. Esas visiones no tienen ningún contenido pertinente. En otras palabras, el hecho de ser negros no los hace descendientes de los esclavos africanos. La identidad por consiguiente no tiene nada que ver con el perfil genético de los grupos.

Si el mestizaje, en tanto que hecho biológico, no presenta en sí ningún interés, por el contrario, no hace falta creer que yo minimizo los efectos culturales y políticos de los mestizajes biológicos, que rara vez se quedan en el mero plano biológico. Porque si los pueblos se encuentran, se reconocen y conviven en el planeta, esto debe tener consecuencias en su desarrollo político y cultural. Pero hay una diferencia entre el hecho de que ellos se relacionen según las leyes del amor (con "a" mayúscula o minúscula) o según las de identidades proclamadas

3 El juego de palabras del que habla Jean Bernabé se da entre mondialisation y immondialisation. Immondialisation es una palabra que bien se puede referir al proceso contrario de mundialización o a immonde (inmundo).

4 Las siglas quieren decir Asociación por la Tasación de las Transacciones financieras y por la Ayuda de los Ciudadanos, un movimiento internacional de antiglobalización que promueve el control político y social de los mercados financieros. N. del T. 
o preestablecidas de castas o de clanes etiquetados según una lógica que se dice identitaria. En este sentido, el concepto de identidad, al mismo tiempo útil y peligroso, debe ser interrogado, interpelado, reconsiderado.

Estos propósitos zanjan una distancia con las elucubraciones modernas sobre el mestizaje y sus virtudes salvadoras, pero también sobre el conformismo unitarista. Contra todos los racismos, contra todos los imperialismos, la poesía de Césaire nos ayuda a mantener el rumbo. No está de más para convencerse de ello, volver a leer el fin del Cuaderno:

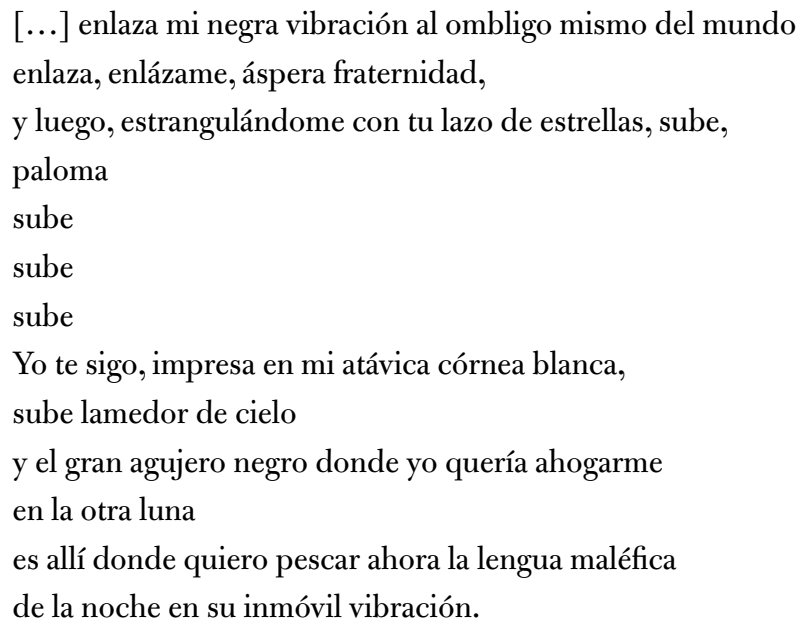

\section{Obras citadas}

Césaire, Aimé. "Cuaderno de un retorno al país natal". Aimé Césaire, poesías. La Habana: Editorial Casa de las Américas, 1969.

Chamoiseau, Patrick, Raphael Confiant y Jean Bernabé. Elogio de la creolidad. París: Editions Gallimard, 1989. 